\title{
Chemical Composition and in vitro Antimicrobial and Antioxidant Activities of Commercially Available Essential Oils against Multidrug Resistant Bacteria
}

\author{
Yeong wol $\mathrm{Yoo}^{1^{+}}$, Hyo Jeong Lee ${ }^{2^{+}}$, Seung $\mathrm{Kim}^{2}$, Min Suk Bae ${ }^{3}$, Mi Ja Lee ${ }^{4}$, Jung-Hyun Shim ${ }^{5 *}$ \\ and Seung Sik $\mathrm{Cho}^{5 *}$
}

\begin{abstract}
${ }^{1}$ Department of Complementary and alternative Medicine, Chosun University, Gwangiu 502-772, Korea, ${ }^{2}$ Departments of Alternative Medicine, Gwangju University, Gwangiu 503-703, Korea, ${ }^{3}$ Department of Environmental Engineering, Mokpo National University, Muan 534-729, Korea, ${ }^{4}$ Department of Pathology, College of Medicine, Chosun University, Gwangju 502-772, Korea, ${ }^{5}$ Department of Pharmacy, College of Pharmacy, Mokpo National University, Muan 534-729, Korea
\end{abstract}

Received January 2, 2014 /Revised March 3, 2014 /Accepted March 10, 2014

\begin{abstract}
In the present study, the chemical compositions and antimicrobial and antioxidant activities of commercially available essential oils in Korea were investigated. The essential oils were analyzed by gas chromatography-mass spectrometry (GC-MS). The results demonstrated that they exhibit a broad spectrum of antimicrobial activities against gram positive, gram negative, and multidrug resistant (MDR) strains. The antimicrobial activity of five of the essential oils against 40 organisms was assessed using the minimum inhibitory concentration (MIC). The MIC values were in the ranges of $0.0625-0.5 \%(\mathrm{v} / \mathrm{w})$ for lemongrass and manuka, $0.03125-1.0 \%(\mathrm{v} / \mathrm{w})$ for tea tree, $0.0625-1.0 \%(\mathrm{v} / \mathrm{w})$ for thyme, and $1-4 \%$ $(\mathrm{v} / \mathrm{w})$ for ravensara, depending on the pathogens studied. This study revealed that, among the essential oils tested, lemongrass and thyme oil showed broad antimicrobial activity against infectious bacteria. The antioxidant activities and the reducing power of the essential oils were determined with a 1, 1-diphenyl-2-picrylhydrazyl (DPPH) assay. Thyme oil exhibited the strongest antioxidant activity comparing with ascorbic acid. This is the first report on the chemical compositions and antimicrobial activities of commercially available essential oils against infectious bacteria and MDR strains acquired from Korean hospitals.
\end{abstract}

Key words : Chromatography-mass spectrometry (GC-MS), essential oil, multidrug resistant bacteria

\section{서 론}

정유는 일반적으로 식물에서 증류방법에 의하여 얻을 수 있는 유기물질이다. 일반적으로 정유는 허브, 꽃, 나무 껍질 등에서 추출할 수 있다[28]. 정유는 방향성, 휘발성의 물질이 며, 보통 항균작용, 부패, 산화방지 등의 효과가 널리 보고되어 있다[20-21, 29]. 또한 정유는 항균, 항 산화 효능 외에도 항 염증, 항 알러지 및 항암 활성을 가지는 것으로 알려져 있어 그 유용성이 주목되고 있다[2, 13, 26-27]. 정유는 오랫동안 천 연 항균 방부제 및 보존제로 사용되고, 연구되어 왔으며, 최근 에는 아로마 테라피와 천연물에 대한 관심이 증대함에 따라 단순한 향유, 공기 정화의 기능뿐 아니라 다양한 치료 목적에 도 이용범위가 확대됨에 따라 그 사용량이 매년 증가하는 추

\footnotetext{
${ }^{+}$Authors contributed equally.

*Corresponding author

Tel : +82-61-450-2687, Fax : +82-61-450-2689

E-mail : sscho@mokpo.ac.kr (Seung Sik Cho) s1004jh@gmail.com (Jung-Hyun Shim)

This is an Open-Access article distributed under the terms of the Creative Commons Attribution Non-Commercial License (http://creativecommons.org/licenses/by-nc/3.0) which permits unrestricted non-commercial use, distribution, and reproduction in any medium, provided the original work is properly cited
}

세에 있다. 특히 항생제 내성균 발생 빈도가 증가함에 따라 천연 항균제의 중요성이 부각됨에 따라 식물 정유의 항균 효 능에 대한 연구 또한 활발히 진행되고 있는 실정이다 $[3,14$, 16]. 최근 국내의 정유 수입 및 사용량이 증가 추세에 있으나, 각 정유 성분에 대한 정확한 성분의 구성 및 함량에 대한 정보 가 부족하여 정유 성분의 올바른 이용에 제한요소가 되고 있 다. 따라서, 본 연구에서는 국내에서 시판 중인 대표적인 정유 5 종을 선정하여, 그 화학성분을 GC-MS를 이용하여 분석하였 고, 최근 분리한 다약제 내성균과 감염성 세균에 대한 항균효 능 평가 및 항산화 효과를 조사하여 비교 분석하였다.

\section{재료 및 방법}

\section{재료 및 시약}

시판 정유로써 lemongrass, manuka, tea tree, ravensara, thyme을 선정하였으며, 모두 G.R. Davis Pty. Ltd. (GR Davis Pty Ltd, Queanbeyan, Australia) 사의 제품을 사용하였다. DPPH (1,1-diephenyl-2-picryl hydrazyl), ascorbic acid, potassium ferricyanide, trichloroacetic acid 및 ferric chloride는 Sigma (Sigma Chemical Co., St. Louis, MO, USA)사의 제품을 사용하였다. 실험에 사용된 모든 용매들은 특급으로 wako 
(Wako Pure Chemical Industries, Osaka, Japan)사로부터 구 입하였다.

\section{사용 균주}

정유 항균활성 검정을 위하여 그람 양성세균은 Enterococcus Faecalis ATCC 29212, Bacillus subtilis ATCC6633, Staphylococcus aureus KCTC 1928, Micrococcus luteus ATCC 9341, Mycrobacterium smegmatis ATCC 9341, Enterococcus faecium ATCC 8043, Staphylococcus aureus subsp. aureus ATCC10537, Staphylococcus aureus KCTC1928 (R209) 및 Staphylococcus aureus ATCC 6538P을 사용하였으며 음성세균은 Alacligenes faecalis ATCC 1004, Salmonella typhimrium KCTC 1925, Escherrichia coli KCTC 1923, Pseudomonas aeruginosa KCTC 1637 및 Enterococcus cloacae ATCC13047를 한국생명공학 연구원생물 자원센터(Korean Collection for Type Culture, KCTC)에서 분 양받아 사용하였다. 다약제 내성균인 MRSA (methicillin resistant Staphylococcus aureus), VRE (vancomycin resistant enterococci), IMP (carbapenemase 생성 imipenem 내성균), ESBL (extended-spectrum $\beta$-lactamase 생성 균)은 순천대학교 생물학과 미생물학 실험실에서 분양 받아 사용하였다.

\section{$\mathrm{GC}$ 및 GC-MS}

정유의 성분을 정성분석하기 위해서 가스크로마토그래피 (Agilent 7890A gas chromatograph (GC))를 사용하였다. 컬럼 은 DB-5계열(30 m×0.25 mm i. d., J\&W Scientific, DB-5 crosslinked 5\% phenylmethyl silicone)을 사용하였다. 컬럼온도는 $50^{\circ} \mathrm{C}$ 에서 5 분간 유지한 후 $250^{\circ} \mathrm{C}$ 까지 분당 $4^{\circ} \mathrm{C}$ 씩 승온시켰다. 주입구 및 검출기의 온도는 각각 $300^{\circ} \mathrm{C}$ 와 $230^{\circ} \mathrm{C}$ 로 하였고, 헬 륨을 운반기체로 사용하여 분당 $1 \mathrm{ml}$ 의 유속을 유지하여 분석 하였다. 컬럼에 의해 분리된 유기 성분의 정성분석을 위해 질 량 분석기(mass spectrometry detector, 5975C, Agilent, USA) 를 사용하여, 이온화된 전자를 EI (electron ionization) 분석 모드에서 질량 분석하였다. 정유의 성분 확인을 위해 이온화 된 전자 분포(spectrum)를 얻은 후 NIST \& Wiley library search data system 및 문헌상의 mass spectral data에 따라 각 성분의 retention indices (RI)를 구하고 이를 문헌상의 RI와 비교하여 동정하였다.

\section{항생물질 감수성 시험(MIC test)}

항생물질 감수성은 $\mathrm{MIC}$ (minimum inhibitory concentration)법으로 평가하였다[4]. 시험균주는 MHB (Mueller hinton broth, Difco사)에 배양하였으며, 최종 $10^{6} \mathrm{CFU} / \mathrm{ml}$ 가 되도 록 조정하였다. 정유는 소량의 메탄올 및 tween 80 에 녹여 syringe filter로 무균 여과하여 $\mathrm{MHB}$ 배지에 섞었을 때 배지내의 정유의 농도가 $4 \sim 0.031 \%(\mathrm{v} / \mathrm{v})$ 가 되도록 조정하여 $36^{\circ} \mathrm{C}$ 에서 24 시간 배양 후 육안으로 관찰하여 균의 성장이 억제된 최저
농도(MIC)를 판별하였다. 사용한 용매와 tween 80 은 시료의 항균력 및 균주 배양에 영향을 미치지 않는 사실을 대조실험 을 통해 확인하였다.

\section{DPPH radical 소거능 평가}

정유의 항산화 활성은 $\mathrm{DPPH}$ 법을 이용하여 측정하였다 [29]. DPPH (1,1-diephenyl-2-picryl hydrazyl) radical 소거능 측정은 안정한 free radical 화합물인 $\mathrm{DPPH}$ 를 기질로 하여 시료의 항산화 능력을 측정하였으며, $517 \mathrm{~nm}$ 에서 광흡수를 나타내는 화합물인 $\mathrm{DPPH}$ 는 항산화 물질에 의해 전자공여 작 용으로 탈색이 되어 흡광도가 감소하여 감소된 흡광도의 변화 를 통하여 항산화 물질의 활성을 측정하였다. 정유성분을 $100 \%$ 메탄올에 녹인 후 희석하여 사용하였으며, 각기 다른 농도의 시료 에 $0.15 \mathrm{mM} \mathrm{DPPH}$ 용액 $100 \mu \mathrm{l}$ 을 첨가하여 잘 혼합하여 30 분 후 $517 \mathrm{~nm}$ 에서 흡광도의 변화를 측정하였다. 대조구는 시료대신 메탄올을 첨가하여 흡광도 변화 정도를 조사하였으며 free radical 소거능은 아래의 식에 의하여 계산 하였다.

Free radical 소거능=(시료의 흡광도/대조구의 흡광도)

$$
\times 100
$$

\section{환원력 평가}

환원력 평가는 정유 시료 $1 \mathrm{ml}$ 에 $200 \mathrm{mM}$ sodium phosphate buffer ( $\mathrm{pH}$ 6.6)와 $10 \%$ potassium ferricyanide를 각각 $1 \mathrm{ml}$ 씩 차례로 첨가한 다음 $50^{\circ} \mathrm{C}$ 에서 20 분간 반응시켰다. 반응 액에 $10 \%$ trichloroacetic acid를 $1 \mathrm{ml}$ 첨가하여 $10,000 \mathrm{~g}$ 에서 10 분간 원심분리를 하고 상층액 $1 \mathrm{ml}$ 에 $0.1 \%$ ferric chloride $1 \mathrm{ml}$ 을 첨가한 후 $700 \mathrm{~nm}$ 에서 흡광도를 측정하여 환원력을 평가하였다[7].

\section{결과 및 고찰}

\section{정유 5 종의 성분 분석}

GC-MS분석을 통하여 5종의 정유의 성분분석을 실시하였 다. Lemongrass의 성분을 분석한 결과, Table 1 에 정리된 바와 같이 terpene aldehyde계열의 향기 물질인 cis-citral이 주 성분 으로 확인되었고, monoterpene인 geraniol acetate 및 camphene이 확인되었다. 또한 a-pinene, caryophyllene도 정유 성 분내에 존재함을 확인하였다. Citral은 Lemon myrtle (90-98\%), Litsea citrata (90\%), Litsea cubeba (70-85\%), lemongrass (65$85 \%)$, lemon tea-tree (70-80\%), Ocimum gratissimum $(66.5 \%)$, Lindera citriodora (65\%), Calypranthes parriculata (about 62\%), petitgrain $(36 \%)$, lemon verbena $(30-35 \%)$, lemon ironbark $(26 \%)$, lemon balm $(11 \%)$, lime $(6-9 \%)$, lemon $(2-5 \%)$ 및 orange 등에 널리 함유되어 있으며 항균 활성을 가지는 것으로 보고되어 있다[6, 10, 17, 25]. Manuka의 성분을 분석한 결과, 
Table 1. Composition of essential oils

\begin{tabular}{|c|c|c|}
\hline & Compound (lemongrass) & $\underset{\%}{\text { Relative }}$ \\
\hline 1 & hexanal & $0.01 \%$ \\
\hline 2 & 3-hexen-1-ol & $0.03 \%$ \\
\hline 3 & 1,6-dimethylhepta-1,3,5-triene & $0.02 \%$ \\
\hline 4 & 1,7,7-trimethyl-tricyclo[2.2.1.0(2,6)] heptane & $0.47 \%$ \\
\hline 5 & 2,6,6-trimethyl-bicyclo[3.1.1]hept-2-ene & $0.38 \%$ \\
\hline 6 & 1s-a-pinene & $0.32 \%$ \\
\hline 7 & camphene & $4.84 \%$ \\
\hline 8 & $\begin{array}{l}\text { 4-methylene-1-(1-methylethyl)-bicylco[3.1.0] } \\
\text { hexane }\end{array}$ & $0.06 \%$ \\
\hline 9 & 6-methyl-5-hepten-2-one & $4.26 \%$ \\
\hline 10 & 1-methyl-4-(1-methylethyl)-cyclohexene & $1.11 \%$ \\
\hline 11 & (e)-3,7-dimethyl-1,3,7-octatriene & $0.48 \%$ \\
\hline 12 & (e)-3,7-dimethyl-1,3,6-octatriene & $0.33 \%$ \\
\hline 13 & (z)-3,7-dimethyl-1,3,6-octatriene & $0.45 \%$ \\
\hline 14 & 4-nonanone & $2.89 \%$ \\
\hline 15 & 3,7-dimethyl-1,6-octadien-3-ol & $1.83 \%$ \\
\hline 16 & 4,4,6,6-tetramethyl-bicyclo[3.1.0]hex-2-ene & $0.73 \%$ \\
\hline 17 & cis-citral & $40.97 \%$ \\
\hline 18 & 2-methoxy-4-vinylphenol & $0.09 \%$ \\
\hline 19 & 2-methylenebornane & $0.05 \%$ \\
\hline 20 & 2,6-dimethyl-2,6-octadiene & $0.08 \%$ \\
\hline 21 & geraniol acetate & $4.99 \%$ \\
\hline 22 & vanillin & $0.05 \%$ \\
\hline 23 & caryophyllene & $1.68 \%$ \\
\hline \multicolumn{3}{|c|}{ Compound (manuka) } \\
\hline 1 & 3-hexen-1-ol & $0.03 \%$ \\
\hline 2 & a-phellandrene & $0.51 \%$ \\
\hline 3 & 2,6,6-trimethyl-bicyclo[3.1.1]hept-2-ene & $1.52 \%$ \\
\hline 4 & 1r-a-pinene & $1.23 \%$ \\
\hline 5 & $\begin{array}{l}\text { 6,6-dimethyl-2-methylene-bicyclo[3.1.1] } \\
\text { heptane }\end{array}$ & $1.02 \%$ \\
\hline 6 & 7-methyl-3-methylene-1,6-octadiene & $0.87 \%$ \\
\hline 7 & 2-methyl-5-(1-methylethyl)-1,3-cyclohexdiene & $0.35 \%$ \\
\hline 8 & 1-phellandrene & $0.12 \%$ \\
\hline 9 & a-terpenene & $5.26 \%$ \\
\hline 10 & $\gamma$-terpenene & $4.70 \%$ \\
\hline 11 & 1-methyl-4-(1-methylethylidene)-cyclohexene & $1.89 \%$ \\
\hline 12 & 3,7-dimethyl-1,6-octadien-3-ol & $0.07 \%$ \\
\hline 13 & 2,6-dimethyl-2,4,6-octatriene & $0.40 \%$ \\
\hline 14 & 1-methyl-4-(1-methylethyl)-3-cyclohexen-1-ol & $0.09 \%$ \\
\hline 15 & 4-methyl-1-(1-methylethyl)-3-cyclohexen-1-ol & $9.48 \%$ \\
\hline 16 & $(-)-(1 \mathrm{~s}, 2 \mathrm{r}, 4 \mathrm{r})-\beta-$ fenchol & $1.36 \%$ \\
\hline 17 & a-copaene & $4.13 \%$ \\
\hline 18 & a-gurjunene & $7.40 \%$ \\
\hline \multicolumn{3}{|c|}{ Compound (ravensara) } \\
\hline 1 & 1r-a-pinene & $14.33 \%$ \\
\hline 2 & 4(10)-thujene & $5.24 \%$ \\
\hline 3 & $\beta$-pinene & $7.21 \%$ \\
\hline 4 & $(+)$-3-caren & $2.21 \%$ \\
\hline 5 & eucalyptol & $19.68 \%$ \\
\hline 6 & $\gamma$-terpinene & $2.51 \%$ \\
\hline 7 & cis- $\beta$-terpineol & $0.13 \%$ \\
\hline
\end{tabular}

\begin{tabular}{|c|c|c|}
\hline \multicolumn{2}{|r|}{ Compound (ravensara) } & $\underset{\%}{\text { Relative }}$ \\
\hline 8 & a-terpinolen & $1.15 \%$ \\
\hline 9 & $\beta$-linalool & $3.46 \%$ \\
\hline 10 & $\begin{array}{l}\text { 4-methyl-1-(1-methylethyl)-3-cyclohexene- } \\
\text { 1-ol }\end{array}$ & $5.90 \%$ \\
\hline 11 & 4-allyl anisole & $5.18 \%$ \\
\hline 12 & a-terpinene & $0.56 \%$ \\
\hline 13 & eugenol & $0.25 \%$ \\
\hline 14 & $(+)$-a-copaene & $1.00 \%$ \\
\hline 15 & methyleugenol & $3.73 \%$ \\
\hline 16 & $\beta$-caryophyllene & $2.58 \%$ \\
\hline 17 & $\begin{array}{l}\text { [s-(e,e)]-1-methyl-5-methylene-8-(1- } \\
\text { methylethyl)-1,6-cyclodecadiene }\end{array}$ & $3.05 \%$ \\
\hline 18 & a-caryophyllene & $1.24 \%$ \\
\hline \multicolumn{3}{|c|}{ Compound(tea tree) } \\
\hline 1 & a-phellandrene & $0.98 \%$ \\
\hline 2 & 1r-a-pinene & $5.87 \%$ \\
\hline 3 & $\beta$-l-pinene & $3.48 \%$ \\
\hline 4 & a-terpinene & $11.25 \%$ \\
\hline 5 & y-terpinene & $11.79 \%$ \\
\hline 6 & a-terpinolen & $3.99 \%$ \\
\hline 7 & 2,6-dimethyl-2,4,6-octatriene & $0.41 \%$ \\
\hline 8 & 1-terpinen-4-ol & $21.38 \%$ \\
\hline 9 & (z)-geraniol & $0.10 \%$ \\
\hline 10 & bicycloelemene & $0.36 \%$ \\
\hline 11 & $\begin{array}{l}\text { 1,3-dimethyl 8-(1-methylethyl)-tricyclo } \\
{[4.4 .0 .0(2,7)] \mathrm{dec}-3 \text {-ene }}\end{array}$ & $1.81 \%$ \\
\hline 12 & (-)-alloaromadendrene & $5.06 \%$ \\
\hline 13 & epiglobulol & $0.47 \%$ \\
\hline 14 & viridiflorol & $1.58 \%$ \\
\hline \multicolumn{3}{|c|}{ Compound (thyme) } \\
\hline 1 & 1s-a-pinene & $0.01 \%$ \\
\hline 2 & $\gamma$-terpinene & $3.21 \%$ \\
\hline 3 & $(+)-(4 r)$ limonene & $0.30 \%$ \\
\hline 4 & $(+)$-sabinene & $3.87 \%$ \\
\hline 5 & $(+)$-3-caren & $3.64 \%$ \\
\hline 6 & $(+)$-linonene & $10.79 \%$ \\
\hline 7 & 4-thujanol & $0.09 \%$ \\
\hline 8 & 4-allyanisole & $7.03 \%$ \\
\hline 9 & (e)-carveol & $0.42 \%$ \\
\hline 10 & geraniol & $4.30 \%$ \\
\hline 11 & cis,trans-citral & $1.04 \%$ \\
\hline 12 & eugenol & $20.57 \%$ \\
\hline 13 & 1,3,4-eugenol & $1.47 \%$ \\
\hline 14 & $(+)$-longifolene & $5.18 \%$ \\
\hline 15 & caryophyllene & $3.69 \%$ \\
\hline 16 & (-)-germacrene & $0.12 \%$ \\
\hline 17 & $(+)$ - $\beta$-selinene & $0.13 \%$ \\
\hline 18 & a-selinene & $0.28 \%$ \\
\hline 19 & $(+,-)-\beta$-bisabolene & $0.26 \%$ \\
\hline 20 & $(+)$ - $\sigma$-cadinene & $0.80 \%$ \\
\hline 21 & 1,3,4-eugenol acetate & $0.54 \%$ \\
\hline 22 & a-bisabolene & $0.07 \%$ \\
\hline
\end{tabular}


Table 2에 정리된 바와 같이 a-gurjunene, a-terpinene, $z$-terpinene, a-coapene, a-pinene, 1-phellandrene이 확인되었다. Manuka는 Leptospermum scoparium 에서 추출한 정유 성분으 로서, 항균 및 항염증 등의 효과를 가지는 것으로 알려져 있으 며, 구성 성분으로 cubebene, copaene, elemene, gurjunene, caryophyllene, selinene, calamenene 및 cadinene계 물질 등 이 알려져 있다[11-12, 18]. Ravensara를 GC-MS로 분석한 결 과는 Table 3에 나타내었으며 eucalyptol, a-pinene, $\beta$-pinene, 4(10)-thujene, 4-allyl anisole, methyleugenol, $\beta$-linalool, acaryophyllene, $\beta$-caryophyllene, $\gamma$-terpinene, $(+)-3$-carene 및 a-coapene 등이 확인되었다[19].

Tea tree 정유 성분의 분석 결과는 Table 4 와 같으며 terpinene-4-ol, $\gamma$-terpinene, a-terpinene, a-pinene, $\beta$-pinene, (-)alloaromadendrene, a-terpinolene, epiglobulol, viridiflorol 및 geraniol이 확인되었다. Thyme 정유 성분의 분석 결과 Eugenol, (+)-linonene, 4-allylanisole, $(+)$-longifolene, geraniol alcohol, $(+)$-sabinene, caryophyllene, $(+)-3$-caren, $\gamma$-terpinene 및 citral이 확인되었다(Table 1).

\section{정유 5 종의 항균활성 평가}

정유 5 종은 다양한 그람 양성세균, 그람 음성세균 및 다제내 성균에 항균활성을 보였으며 Fig. 3 에 IMP 균주에 대한 항균 력을 나타내었다. 그람 양성세균, 그람 음성세균 및 다제내성 균을 대상으로 시판 정유 5종의 항균활성을 조사한 결과는 Table 2에 나타내었다. 정유 5종 모두 그람 양성세균 및 그람 음성세균에 고른 항균 스펙트럼을 보였다. Lemongrass의 경 우 5종의 그람 음성세균에 대해 $0.0625-0.125 \%(\mathrm{v} / \mathrm{v})$ 의 MIC 값을 보였으며, MRSA, VRE, IMP, ESBL에 대해 0.125-0.25\% $(\mathrm{v} / \mathrm{v})$ 의 고른 항균 스펙트럼을 보였으나, 최근 분리한 임상 균주 중 일부 IMP 균주에는 항균활성을 보이지 않았다. Manuka의 경우에는 그람 음성세균에는 MIC가 0.5-1\% (v/v) 이었으며, E. cloacae에서는 $1 \%(\mathrm{v} / \mathrm{v})$ 이상의 $\mathrm{MIC}$ 값을 보였다. Manuka는 MRSA, VRE와 일부 IMP 균주에서 0.0625-0.125\% $(\mathrm{v} / \mathrm{v})$ 의 고른 항균 스펙트럼을 보였으나, ESBL균주에 대해서 는 항균활성을 보이지 않았다. Ravensara의 경우에는 모든 시 험 균주에서 2-4\% (v/v)의 높은 MIC값을 보여주었으며, 특히 $\mathrm{VRE}, \mathrm{ESBL}$ 균주에서는 $\mathrm{MIC}$ 값이 $4 \%(\mathrm{v} / \mathrm{v})$ 이상으로 나와 항 균활성을 보이지 않았다. Tea tree 정유의 경우에는 시험 균주 중 그람 음성세균 및 $\mathrm{ESBL}$ 에서는 $0.5 \%(\mathrm{v} / \mathrm{v})$ 의 $\mathrm{MIC}$ 값을 나타 내었으며, MRSA와 VRE 균주에 대해 $0.025-1 \%(\mathrm{v} / \mathrm{v})$ 범위의 MIC 값을 보여주었다. Thyme 정유는 모든 시험 균주에 대해 항균활성을 나타내어 가장 항균 범위가 넓은 것으로 확인되었 다. 그람 음성세균에 대해서는 $0.5-1 \%(\mathrm{v} / \mathrm{v})$ 의 MIC값을 보였 으며, MRSA와 VRE에 0.5-1\% (v/v), IMP에 대해서는 0.125$0.5 \%(\mathrm{v} / \mathrm{v})$, ESBL에 대해서는 $0.5-1 \%(\mathrm{v} / \mathrm{v})$ 의 고른 MIC값을 나타내었다. 5종의 정유들을 비교한 결과, lemongrass 및 thyme 정유의 항균 범위가 가장 넓었고, manuka의 경우에는 최근 분리한 임상 균주인 MRSA 및 VRE에 대해 가장 낮은 MIC 수치를 보였다. Lis-Balchin 등은 정유의 성분 중에 apinene, terpinene-4-ol, a-terpinene, $\beta$-terpinene, $\mathrm{\gamma}$-terpinene 등이 그람 음성세균 및 그람 양성세균에 넓은 항균활성을 가 지고 있는 것으로 보고하였으며, terpinene 중에는 a-terpinene과 $\beta$-terpinene의 항균력이 우수하며 $\gamma$-terpinene은 낮은 항균활성을 가지는 것으로 보고하였다. Terpinene-4-ol 및 1.8-cineol도 다양한 병원 미생물에 항균활성을 가지는 것으로 보고되었다[11, 22]. Tea tree에는 항균 성분인 terpinene-4-ol (21.38\%), a-terpinene $(11.25 \%)$, a-pinene $(5.87 \%)$ 이 높은 함유 량을 보였으며, ravensara에도 역시 a-pinene $(14.33 \%)$ 이 높은 함유량을 보였으나, manuka, lemongrass 및 thyme과 비교 시에는 다약제 내성균에 대해 높은 MIC 값을 보였다. Manuka 의 경우에는 a-pinene (1.23\%), a-terpinene $(5.26 \%)$, a-copaene $(4.13 \%)$ 및 phellandrene $(0.12 \%)$ 을 함유하고 있는데, a-copaene은 B. subtilis, S. aureus 등의 세균에 항균활성을 보이는 것으로 보고되어 있으며, phellandrene 또한 S. aureus나 Candida albicans에 대해 항균활성이 있는 것으로 보고되어 있 다 [8, 24].

Ravensara 정유 성분 중 a-pinene $(14.33 \%)$, a-terpinene (0.56\%), a-caryophyllene (1.24\%), $\beta$-caryophyllene $(2.58 \%)$, a -copaene $(1.0 \%)$, Eugenol $(0.25 \%)$ 이 항균 효과와 관련이 있는 데 $\beta$-caryophyllene의 항균활성에 대해서는 많은 보고가 있으 며, 특히 광산화된 $\beta$-caryophyllene은 그 항균활성이 증가하 는 것으로 보고되어 있다[9]. Eugenol은 그람 양성세균 및 음 성세균에 대해서 광범위한 항균활성을 가지는 것으로 보고되 어 있으며, 다양한 물질들과 함께 사용할 경우에 항균활성이 상승되는 것으로 알려져 있다[15, 23]. (+)-3-Cearen과 $\beta$-linalool은 S. aureus, E. coli, P. aeruginosa, K. pneumonia 및 C. albicans에 대해 항균활성이 있는 것으로 보고되어 있다 $[1,5,15$, 23]. Tea tree의 성분 중에는 a-pinene $(5.87 \%)$, a-terpinene $(11.25 \%)$ 및 terpinene-4-ol $(21.38 \%)$ 이 확인되었는데, 이들 성 분들의 상승 효과로 다약제 내성균에 대해 높은 항균활성을 나타내는 것으로 생각된다. Thyme 정유는 항균 성분인 Eugenol $(20.57 \%)$, caryophyllene $(1.24 \%)$, caryophyllene $(3.69 \%)$, (+)-3-caren (3.64\%) 및 (E)-carveol (0.42\%)을 함유하고 있었으 며 5종의 정유 중에서 가장 넓은 항균 스펙트럼을 보여주었다.

\section{정유 5 종의 항산화 효능 평가}

Fig. 1에 제시된 바와 같이 5종의 정유는 DPPH free radical 의 저해 활성을 나타냈으며, 농도 의존적으로 활성이 증가되 었다. Lemongrass $(100 \mu \mathrm{g} / \mathrm{ml}, 56.7 \%)$, manuka $(200 \mu \mathrm{g} / \mathrm{ml}$, $44.4 \%)$, ravensara $(500 \mu \mathrm{g} / \mathrm{ml}, 39.8 \%)$ 및 tea tree $(500 \mu \mathrm{g} / \mathrm{ml}$, $14 \%$ )는 ascorbic acid에 비해서는 현저히 낮은 억제 활성을 나타냈다. 그러나 $2 \mu \mathrm{g} / \mathrm{ml}$ 의 농도에서 DPPH free radical 저 
Table 2. MIC (minimum inhibitory concentration) of essential oils against various bacterial strains

\begin{tabular}{|c|c|c|c|c|c|c|}
\hline Gram & Organisms & Lemongrass & Manuka & Ravensara & Tea tree & Thyme \\
\hline- & Alacligenes faecalis ATCC 1004 & 0.0625 & 0.5 & 4 & 0.5 & 0.25 \\
\hline- & Enterococcus cloacea & 0.25 & $>1$ & $>4$ & 0.5 & 0.5 \\
\hline- & Salmonella typhimrium KCTC 1925 & 0.125 & 1 & 4 & 0.5 & 0.125 \\
\hline- & Escherrichia coli KCTC 1923 & 0.125 & 1 & 4 & 0.5 & 0.5 \\
\hline- & Pseudomonas aeruginosa КСТC & 0.0625 & 0.0625 & 4 & 0.5 & 0.5 \\
\hline+ & Enterococcus Faecalis ATCC 29212 & 0.125 & 0.0625 & 4 & $>1$ & 0.25 \\
\hline+ & Enterococcus faecium & 0.25 & $>1$ & $>4$ & 0.5 & 0.5 \\
\hline+ & Bacillus subtilis ATCC6633 & 0.031 & 0.125 & 2 & 0.125 & 0.0625 \\
\hline+ & Micrococcus luteus ATCC 9341 & 0.031 & 0.0625 & 2 & 0.5 & 0.0625 \\
\hline+ & Mycrobacterium smegmatis ATCC 9341 & 0.031 & 1 & 2 & 0.25 & 0.0625 \\
\hline+ & Staphylococcus aureus KCTC 1928 & 0.0625 & 0.0625 & 4 & 0.5 & 0.125 \\
\hline+ & Staphylococcus aureus subsp. aureus ATCC10537 & 0.5 & 0.0625 & 1 & 0.5 & 0.25 \\
\hline+ & Staphylococcus aureus ATCC 6538p & 0.5 & 0.125 & 1 & 0.5 & 0.25 \\
\hline+ & MRSA 693E & 0.125 & 0.0625 & 2 & 0.025 & 0.25 \\
\hline+ & MRSA 4-5 & 0.125 & 0.0625 & 1 & 0.025 & 0.25 \\
\hline+ & MRSA 5-3 & 0.125 & 0.0625 & 2 & 0.025 & 0.25 \\
\hline+ & MRSA S1 & 0.25 & 0.0625 & 4 & 1 & 0.5 \\
\hline+ & MRSA S3 & 0.25 & 0.0625 & 4 & 1 & 0.5 \\
\hline+ & MRSA U4 & 0.25 & 0.0625 & 2 & 0.025 & 0.5 \\
\hline+ & MRSA P8 & 0.25 & 0.0625 & 2 & 1 & 0.5 \\
\hline+ & MRSA B15 & 0.25 & 0.0625 & 2 & 1 & 0.5 \\
\hline+ & VRSA (MRSA2-32) & 0.25 & 0.0625 & 2 & 1 & 0.25 \\
\hline+ & VRE 82 & 0.25 & 0.0625 & 2 & 1 & 0.5 \\
\hline+ & VRE 89 & 0.25 & 0.0625 & 2 & 1 & 0.5 \\
\hline+ & VRE 98 & 0.25 & 0.0625 & 2 & 1 & 0.5 \\
\hline+ & VRE 2 & 0.125 & 0.125 & 4 & 0.5 & 0.25 \\
\hline+ & VRE 3 & 0.125 & 0.125 & $>4$ & 0.5 & 0.5 \\
\hline+ & VRE 4 & 0.125 & 0.125 & $>4$ & 0.5 & 0.5 \\
\hline+ & VRE 5 & 0.125 & 0.125 & $>4$ & 0.5 & 0.5 \\
\hline \multirow[t]{11}{*}{+} & VRE 6 & 0.25 & 0.125 & $>4$ & 1 & 0.5 \\
\hline & IMP 100 & 0.25 & 0.0625 & 2 & 0.0625 & 0.125 \\
\hline & IMP 102 & 0.25 & 0.0625 & 2 & 0.0625 & 0.125 \\
\hline & IMP 120 & $>1$ & $>1$ & 4 & $>1$ & 0.125 \\
\hline & IMP 123 & $>1$ & $>1$ & 4 & 1 & 0.5 \\
\hline & IMP 129 & 0.125 & 0.5 & 4 & 0.5 & 0.25 \\
\hline & ESBL LMH-B1 & 0.25 & $>1$ & $>4$ & 0.5 & 0.5 \\
\hline & ESBL LMH-P3 & 0.25 & $>1$ & $>4$ & 0.5 & 0.5 \\
\hline & ESBL LMH-S1 & 0.25 & $>1$ & $>4$ & 0.5 & 1 \\
\hline & ESBL LMH-U4 & 0.25 & $>1$ & $>4$ & 0.5 & 0.5 \\
\hline & ESBL LMH-W1 & 0.25 & $>1$ & $>4$ & 0.5 & 1 \\
\hline
\end{tabular}




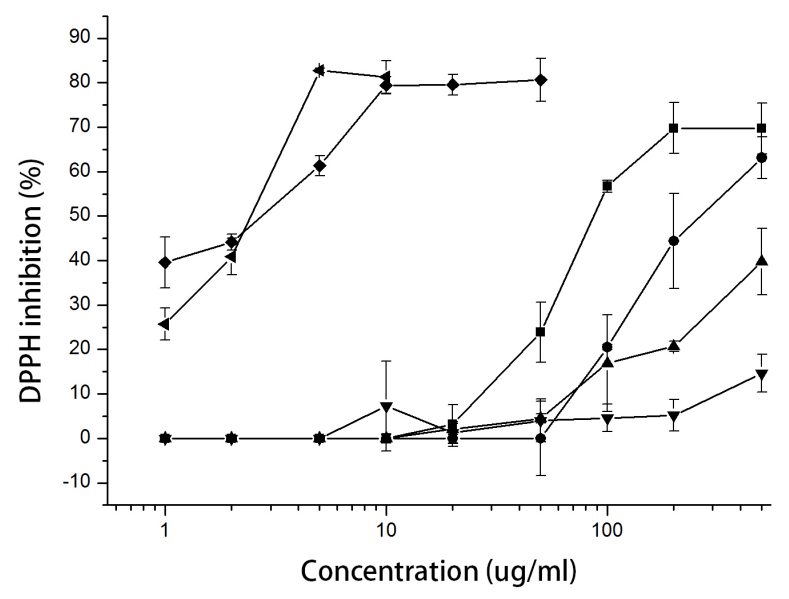

Fig. 1. DPPH radical scavenging activities of essential oils. Ascorbic acid was taken as the standard antioxidant. Samples taken from the range of 10-1,000 $\mu \mathrm{g} / \mathrm{ml}$. Each value is expressed as mean \pm standard deviation $(n=3)$. - $\boldsymbol{0}$-: lemongrass, - $\mathbf{-}$-: manuka, $\mathbf{-} \boldsymbol{\Delta}$-: ravensara, $-\boldsymbol{\nabla}$-: tea tree,

해도를 비교했을 때, thyme (44.14\%)은 ascorbic acid (40.9\%) 와 유사한 항산화능을 보였다. 많은 경우에 천연항산화제는 합성 항산화제보다 작용이 약하나, thyme은 천연 항산화제로 서의 가치가 높다고 생각된다.

또한 환원력 실험을 통해 정유 5 종의 항산화능을 측정하였 으며 그 결과는 Fig. 2와 같다. Fig. 2에 나타난 바와 같이 정유 는 농도 의존적인 환원력을 보였으며 환원력의 크기는 thyme $>$ manuka $>$ lemongrass $=$ tea tree $>$ ravensara 순이었다. 정유 5종 모두 대조물로 ascorbic acid와 비교시에는 높은 환원 력을 보였다.

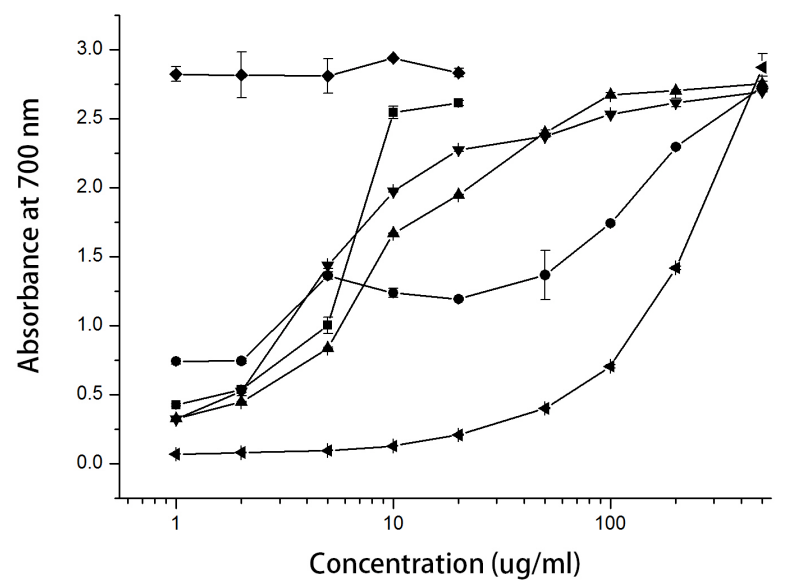

Fig. 2. Reducing powers of essential oils. The absorbance $(700$ $\mathrm{nm})$ was plotted against concentration of sample. All values are mean \pm SD of triplicates. $(n=3)$. - $-\mathbf{-}$ : lemongrass, - -: manuka, $-\boldsymbol{\Delta}$-: ravensara, $-\boldsymbol{\nabla}$-: tea tree, $-\boldsymbol{-}$-: thyme, -4: ascorbic acid.

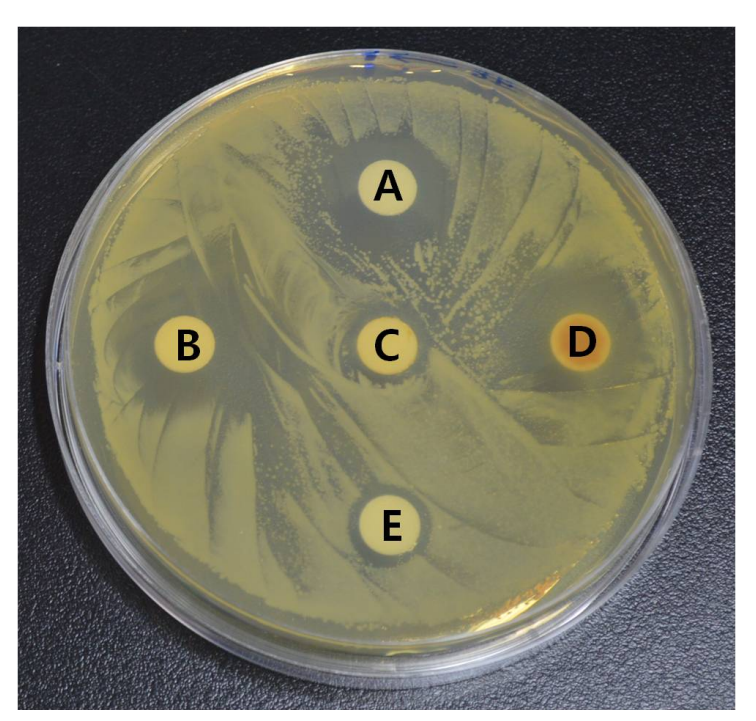

Fig. 3. Antimicrobial activities of essential oils against IMP123. Antimicrobial susceptibility was tested using paper disc agar diffusion method. Paper discs $(8 \mathrm{~mm})$ were soaked in essential oils at the rate of $40 \mathrm{ul}$ per disc for antimicrobial analysis. (A) tea tree, (B) thyme, (C) manuka, (D) lemongrass, (E) ravensara.

Lemongrass는 $1 \mu \mathrm{gg} / \mathrm{ml}$ 의 농도에서, ravensara 및 tea tree 는 $2 \mu \mathrm{g} / \mathrm{ml}$ 의 농도에서는 $50 \mu \mathrm{g}$ ascorbic acid eq. $/ \mathrm{ml}$ 에 해당 하는 환원력을 나타냈으며, manuka는 $1 \mu \mathrm{g} / \mathrm{ml}$ 의 농도에서는 $100 \mu \mathrm{g}$ ascorbic acid eq./ml에 해당하는 환원력을 나타내었 다. Thyme의 경우에는 $1 \mu \mathrm{g} / \mathrm{ml}$ 의 농도에서는 $500 \mu \mathrm{g}$ ascorbic acid eq./ml에 해당하는 환원력을 보여 정유들 중에서 가장 높은 환원력을 보였다.

본 연구에서는 시판중인 정유 5 종을 GC-MS 분석을 통하여 성분을 분석하였다. 또한 일반세균 및 다약제 내성 세균에 대 한 항균활성과 항산화능을 평가하였다. Lemongrass의 경우에 는 일부 $\mathrm{IMP}$ 를 제외한 모든 시험 균주에서 고른 항균 스펙트 럼을 보였으며 MIC 값은 0.0625-0.25\%였다. Manuka 정유는 lemongrass와 비슷한 항균활성을 가지고 있으나, ESBL 균주 에 대해서는 항균활성을 보이지 않았다. Ravensara 정유는 고 른 항균 스펙트럼을 나타내었지만, 다른 정유들과 비교 시에 는 낮은 MIC 값(2-4\%)을 보여주었다. Tea tree 정유는 0.025 $1 \%$ 범위에서 E. faccalis ATCC 29212 및 IMP 120 균주를 제외 한 모든 균주에서 항균력을 보여주었다. Thyme 정유는 모든 시험균주에 감수성을 가지고 있었으며 MIC 값은 0.0625-1\%였 다. 항산화 효능평가 결과, 5 종의 정유 모두 농도 의존적으로 $\mathrm{DPPH}$ free radical 저해 및 환원력을 가지고 있었으며, thyme 이 가장 높은 항 산화능을 보였다. 이상의 결과를 종합하였을 때 5 종의 정유들은 모두 고른 항균 및 항산화능을 가지고 있으 며, 이 중 thyme이 가장 높은 항균활성 및 항산화능을 가지고 있어 천연 항균 항산화제로써의 가치가 있다고 생각되었다. 본 연구진은 GC-MS 분석을 통해 정유 속에 다양한 항균활성 
물질이 존재함을 확인하였고, 정유의 일반세균 및 다약제 내 성균에 대한 강력한 항균작용 역시 항균활성 물질간의 상승효 과에 기인한다고 기존 문헌을 토대로 예측하였다. 그러나 정 확한 항균활성 물질들간의 상승효과를 규명하기 위해서는 앞 으로 지속적인 연구가 필요할 것으로 사료된다.

\section{감사의 글}

본 논문은 2013 학년도 목포대학교 교내연구비 지원(20130159)에 의하여 연구되었으며 이에 감사드립니다.

\section{References}

1. Bevilacqua, A., Corbo, M. R. and Sinigaglia, M. 2010. In vitro evaluation of the antimicrobial activity of eugenol, limonene, and citrus extract against bacteria and yeasts, representative of the spoiling microflora of fruit juices. J Food Prot 73, 888-894.

2. Caldefie-Chezet, F., Guerry, M., Chalchat, J. C., Fusillier, C., Vasson, M. P. and Guillot, J. 2004. Anti-inflammatory effects of Melaleuca alternifolia essential oil on human polymorphonuclear neutrophils and monocytes. Free Rad Res 38, 805-811.

3. Carson, C. F., Cookson, B. D., Farrelly, H. D. and Riley, T. V. 1995. Susceptibility of methicillin-resistant Staphylococcus aureus to the essential oil of Melaleuca alternifolia. J Antimicrob Chem 35, 421-424.

4. Clinical and Laboratory Standards Institute: Performance standards for antimicrobial susceptibility testing; seventh informational supplement. 2007. 27, pp. 98-114, USA.

5. Didry, N., Dubreuil, L. and Pinkas, M. 1994. Activity of thymol, carvacrol, cinnamaldehyde and eugenol on oral bacteria. Pharm Acta Helv 69, 25-28.

6. Fenaroli, G., Furia, T. E. and Bellanca, N. 2009. Handbook of Flavor Ingredients, 6th eds., CRC press, Florida, USA.

7. Hazra, B., Biswas, S. and Mandal, N. 2008. Antioxidant and free radical scavenging activity of Spondias pinnata. BMC Compl Altern Med 8, 63.

8. Iscan, G., Kirimer, N., Demirci, F., Demirci, B., Noma, Y. and Baser, K. H. 2012. Biotransformation of (-)-(R)-alphaphellandrene: antimicrobial activity of its major metabolite. Chem Biodivers 9, 1525-1532.

9. Kim, Y. S., Park, S. J., Lee, E. J., Cerbo, R. M., Lee, S. M., Ryu, C. H., Kim, G. S., Kim, J. O. and Ha, Y. L. 2008. Antibacterial compounds from Rose Bengal-sensitized photooxidation of beta-caryophyllene. J Food Sci 73, C540-545.

10. Lawless, J. 1995. The Illustrated Encyclopedia of Essential Oils. pp. 167, Element Books Ltd., Rockport MA, USA.

11. Lis-Balchin, M., Hart, S. L. and Deans, S. G. 2000. Pharmacological and antimicrobial studies on different tea-tree oils (Melaleuca alternifolia, Leptospermum scoparium or Manuka and Kunzea ericoides or Kanuka), originating in Australia and New Zealand. Phytother Res 14, 623-629.
12. Maddocks-Jennings, W., Wilkinson, J. M., Cavanagh, H. M. and Shillington, D. 2009. Evaluating the effects of the essential oils Leptospermum scoparium (manuka) and Kunzea ericoides (kanuka) on radiotherapy induced mucositis: a randomized, placebo controlled feasibility study. Eur J Oncol Nurs 13, 87-93.

13. Medeiros, R., Passos, G. F., Vitor, C. E., Koepp, J., Mazzuco, T. L., Pianowski, L. F., Campos, M. M. and Calixto, J. B. 2007. Effect of two active compounds obtained from the essential oil of Cordia verbenacea on the acute inflammatory responses elicited by LPS in the rat paw. Br J Pharmacol 151, 618-627.

14. Muthaiyan, A., Martin, E. M., Natesan, S., Crandall, P. G., Wilkinson, B. J. and Ricke, S. C. 2012. Antimicrobial effect and mode of action of terpeneless cold-pressed Valencia orange essential oil on methicillin-resistant Staphylococcus aureus. J Appl Microbiol 112, 1020-1033.

15. Narayanan, A., Neera, Mallesha and Ramana, K. V. 2013. Synergized antimicrobial activity of eugenol incorporated polyhydroxybutyrate films against food spoilage microorganisms in conjunction with pediocin. Appl Biochem Biotechnol 170, 1379-1388.

16. Nostro, A., Blanco, A. R., Cannatelli, M. A., Enea, V., Flamini, G., Morelli, I., Sudano Roccaro, A. and Alonzo, V. 2004. Susceptibility of methicillin-resistant staphylococci to oregano essential oil, carvacrol and thymol. FEMS Microbiol Lett 230, 191-195.

17. Onawunmi, G. O. 1989. Evaluation of the antimicrobial activity of citral. Lett Appl Microbiol 9, 105-108.

18. Porter, N. G. and Wilkins, A. L. 1999. Chemical, physical and antimicrobial properties of essential oils of Leptospermum scoparium and Kunzea ericoides. Phytochemistry 50, 407415.

19. Raharivelomanana, P. J., Terrom, G. P., Bianchini, J. P. and Coulanges, P. 1989. Study of the antimicrobial action of various essential oils extracted from Malagasy plants. II: Lauraceae. Arch Isnt Pasteur Madagascar 56, 261-271.

20. Raman, A., Weir, U. and Bloomfield, S. F. 1995. Antimicrobial effects of tea-tree oil and its major components on Staphylococcus aureus, Staph epidermidis and Propionibacterium acnes. Lett Appl Microbiol 21, 242-245.

21. Rashid, S., Rather, M. A., Shah, W. A. and Bhat, B. A. 2013. Chemical composition, antimicrobial, cytotoxic and antioxidant activities of the essential oil of Artemisia indica Willd. Food Chem 138, 693-700.

22. Schmidta, E., Jirovetzb, L., Buchbauerb, G., Denkovac, Z., Stoyanovac, A., Murgovc, I. and Geisslerd, M. 2005. Antimicrobial testings and gas chromatographic analyses of aroma chemicals. J Essent Oil Bear PI 8, 99-106.

23. Shah, B., Davidson, P. M. and Zhong, Q. 2013. Nanodispersed eugenol has improved antimicrobial activity against Escherichia coli O157:H7 and Listeria monocytogenes in bovine milk. Int J Food Microbiol 161, 53-59.

24. Solís, C., Becerra, J., Flores, C., Robledo, J. and Silva, M. 2004. Antibacterial and antifungal terpens from Pilgerodendron uviferum (D. DON) FLORIN. J Chil Chem Soc 49, 157-161. 
25. Stevens, K. L., Jurd, L., King, A. D., Jr. and Mihara, K. 1971. The antimicrobial activity of citral. Experientia 27, 600-602.

26. Su, Y. C. and Ho, C. L. 2013. Composition, in-vitro anticancer, and antimicrobial activities of the leaf essential oil of Machilus mushaensis from Taiwan. Nat Prod Commun 8, 273-275.

27. Sylvestre, M., Pichette, A., Longtin, A., Nagau, F. and Legault, J. 2006. Essential oil analysis and anticancer activity of leaf essential oil of Croton flavens L. from Guadeloupe.
J Ethnopharmacol 103, 99-102.

28. Tisserand, R. and Balacs, T. 1996. Essential oil safety: A guide for health care professionals. pp. 5-23, Churchill Livingstone, Oxford, UK.

29. Wang, J., Liu, H., Zhao, J., Gao, H., Zhou, L., Liu, Z., Chen, Y. and Sui, P. 2010. Antimicrobial and antioxidant activities of the root bark essential oil of Periploca sepium and its main component 2-hydroxy-4-methoxybenzaldehyde. Molecules $15,5807-5817$.

\section{초록 : 시판 정유의 성분 분석과 다약제 내성균에 대한 항균활성 및 항산화 효능 평가}

유영월 ${ }^{1} \cdot$ 이효정 ${ }^{2} \cdot$ 김 승 $^{2} \cdot$ 배민석 $^{3} \cdot$ 이미자 ${ }^{4} \cdot$ 심정현 $^{5 *} \cdot$ 조승식 ${ }^{5 *}$

( ${ }^{1}$ 조선대학교 대체의학과, ${ }^{2}$ 광주대학교 대체의학과, ${ }^{3}$ 목포대학교 환경공학과, ${ }^{4}$ 조선대학교 의과대학 병리학교 실, ${ }^{5}$ 목포대학교 약학과)

본 연구에서는 국내 시판 중인 정유의 화학적 구성, 항균 및 항산화 효과를 조사하였다. 정유의 성분 분석은 GC-MS법을 이용하였다. 정유는 그람음성, 양성 및 다약제 내성균에 대하여 광범위한 항균 범위를 보여주었다. 정유 5종의 항균활성은 40개 병원성 세균에 대한 MIC로 측정하였다. Lemongrass와 manuka는 0.0625-0.5\% (v/ $\mathrm{w})$, tea tree는 $0.03125-1.0 \%(\mathrm{v} / \mathrm{w})$, thyme $0.0625-1.0 \%(\mathrm{v} / \mathrm{w})$ 및 ravensara는 $1-4 \%(\mathrm{v} / \mathrm{w})$ 의 MIC 수치를 나타내었 다. 정유의 항산화 활성은 환원력 및 $\mathrm{DPPH}$ 법으로 평가하였다. 5 종의 정유 모두 농도 의존적으로 $\mathrm{DPPH}$ free radi$\mathrm{cal}$ 저해 및 환원력을 가지고 있었으며, thyme이 대조군인 ascorbic acid와 비교 시 가장 높은 항 산화능을 보였다. 5 종의 정유 모두 고른 항균 및 항산화능을 가지고 있으며, 이중 thyme이 가장 높은 항균활성 및 항산화능을 가지 고 있어 천연 항균 항산화제로써의 가치가 있다고 생각되었다. 본 연구진은 국내 시판중인 정유 5 종의 성분분석, 항균 및 항산화 활성을 처음으로 비교 분석하여 보고하였다. 